\title{
Decolorization of Dye Water by Hydrogen Peroxide with CuS Micro-Flake as Catalyst
}

Liwei Mí2, Zhen Li ${ }^{1,2}$, Cuilian Wang ${ }^{1}$, Jianmin Zhang ${ }^{1}$, Zhi Zheng ${ }^{2}$ and Weihua Chen ${ }^{1 *}$

${ }^{1}$ College of Chemistry and Molecular Engineering, Zhengzhou University, Zhengzhou, 450001, P. R. China

${ }^{2}$ Key Laboratory for Micro-Nano Energy Storage and Conversion Materials of Henan Province, Institute of Surface Micro and Nano Materials, Xuchang University, Henan, 461000, P. R. China

\begin{abstract}
In this study, CuS micro-flake with average sizes of about 5-10 $\mu \mathrm{m}$ grows on 3D copper foam was synthesized by solvothermal method. This material was characterized using X-ray diffraction (XRD) and scanning electron microscopy (SEM). Besides, this CuS material was used to degrade methylene blue (MB) dye, water as catalyst and the effect of reaction temperature was also discussed.
\end{abstract}

Keywords: X-ray Diffraction (XRD); Scanning Electron Microscopy (SEM); Methylene Blue (MB)

\section{Introduction}

Decolorization of dye wastewater as potential environmental pollutant attracted considerable attention in the past two decades [1-3]. In order to degrade toxic substances in dye wastewater, many approaches have been developed in recent years [4-6]. As far as we know, the most feasible and economical method is $\mathrm{H}_{2} \mathrm{O}_{2}$ catalytic oxidation, with transition metal oxides and sulfides as catalysts $[7,8] . \mathrm{CuS}$ is one of these materials having a wide range of potential applications in nonlinear optical devices, solar radiation absorbers, high capacity cathode materials and photocatalysts [9-11]. Recently, we have succeeded in synthesizing $\mathrm{CuS}$ with different morphologies and decoloring methylene blue (MB) as catalysts [12], but did not relate the effect of temperature on catalyst for dye decolorization. Here, we describe a facile route to $\mathrm{CuS}$ micro-flake structure grow on $3 \mathrm{D}$ copper foam, and studied this material as catalyst for the degradation of methylene blue (MB) on different temperatures.

\section{Experimental}

In this approach, a piece of copper foam $(1 \times 1 \mathrm{~cm}$; Thickness: 1 $\mathrm{mm} ; 0.09 \mathrm{~g}$ ) which used as the template and about $0.09 \mathrm{~g}$ sulfur powder were first loaded into a $20 \mathrm{ml}$ Teflon-lined autoclave, then $11 \mathrm{ml}$ ethylenediamine and $5 \mathrm{ml}$ ethylene glycol was added. The autoclave was maintained at $160^{\circ} \mathrm{C}$ for $24 \mathrm{~h}$ and cooled to room temperature naturally. The dark product was put in carbon disulfide for more than half an hour, then washed with distilled water and alcohol in sequence for three times separately, and dried in an oven at $60^{\circ} \mathrm{C}$.

\section{Results and Discussion}

The phase composition and crystal structure of CuS product was first examined using X-ray diffraction (XRD) analysis (Figure 1). All primary diffraction peaks of the curve are in good agreement with the standard data of CuS (JCPDS No.06-0464). The cell parameters of the product are $a=3.792 \AA$ and $c=16.344 \AA$, indicating the high purity of the obtained sample.

The morphology and structure of the CuS micro-structure were investigated by SEM. Figure 2a shows the low-magnification SEM image of $\mathrm{CuS}$, we can see that many $\mathrm{CuS}$ micro-structure grown and maintained the original foam-like structure very well. The highmagnification SEM image (Figure $2 b$ ) reveals that the as-prepared CuS sample consists of many micro-flakes with each diameter distribution of 5-10 $\mu \mathrm{m}$, and the thickness of this CuS sample is about 2-3 $\mu \mathrm{m}$.

Here, the as-prepared CuS material $(0.06 \mathrm{~g})$ was used to decolorize $5 \mathrm{mg} / \mathrm{L}(30 \mathrm{~mL}) \mathrm{MB}$ with the assistance of $\mathrm{H}_{2} \mathrm{O}_{2}(10 \mathrm{~mL})$ on $5^{\circ} \mathrm{C}$ and $30^{\circ} \mathrm{C}$, separately. Changes in UV-vis spectra during the removal of $\mathrm{MB}$ by as-obtained $\mathrm{CuS}$ are illustrated in Figure 3. We can see that when the temperature was $5^{\circ} \mathrm{C}$, it needed more than $80 \mathrm{~min}$ that the MB's decoloring degree can reach to $95 \%$. Under the same conditions (expect temperature), the decoloring rate of MB can exceed $95 \%$ after only 25 min when the temperature is $30^{\circ} \mathrm{C}$. Based on these experimental datas,

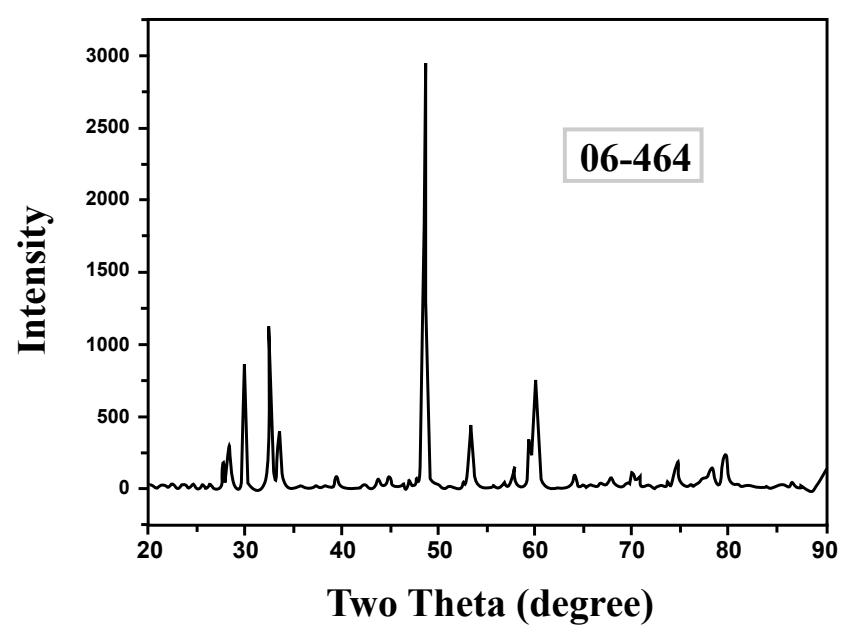

Figure 1: The PXRD pattern of CuS products synthesized at $160^{\circ} \mathrm{C}$ for $24 \mathrm{~h}$.

*Corresponding author: Weihua Chen, College of Chemistry and Molecular Engineering, Zhengzhou University, Zhengzhou, 450001, P. R. China, E-mail: chenweih@zzu.edu.cn

Received June 22, 2012; Accepted July 11, 2012; Published July 15, 2012

Citation: Mi L, Li Z, Wang C, Zhang J, Zheng Z, et al. (2012) Decolorization of Dye Water by Hydrogen Peroxide with CuS Micro-Flake as Catalyst. J Environ Anal Toxicol 2:151. doi:10.4172/2161-0525.1000151

Copyright: (c) $2012 \mathrm{Mi} \mathrm{L}$, et al. This is an open-access article distributed under the terms of the Creative Commons Attribution License, which permits unrestricted use, distribution, and reproduction in any medium, provided the original author and source are credited. 
Citation: Mi L, Li Z, Wang C, Zhang J, Zheng Z, et al. (2012) Decolorization of Dye Water by Hydrogen Peroxide with CuS Micro-Flake as Catalyst. J Environ Anal Toxicol 2:151. doi:10.4172/2161-0525.1000151

Page 2 of 6

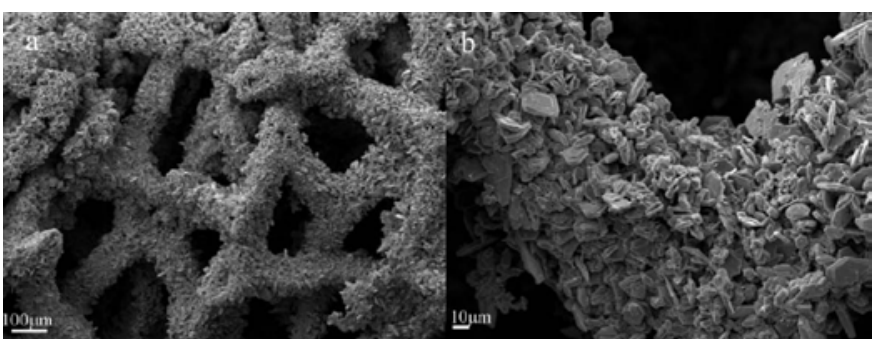

Figure 2: (a) Low-magnification SEM image of CuS (200 times) and (b) for 1000 times.
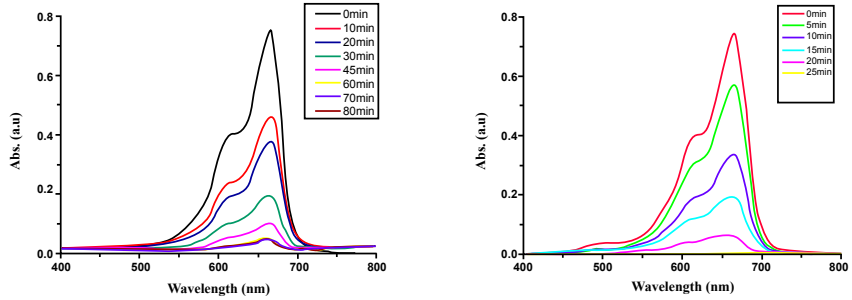

Figure 3: (a) Changes of UV-vis spectra during the removal of MB by asobtained $\mathrm{CuS}\left(5^{\circ} \mathrm{C}\right)$ and (b) $30^{\circ} \mathrm{C}$.

to sum up, the decoloring degree of $\mathrm{MB}$ could be influenced mostly by the reaction temperature.

\section{Conclusions}

In conclusion, $\mathrm{CuS}$ micro-flake has been successfully fabricated within template by using the solvothermal method. Ethylenediamine and ethylene glycol were used as mixed solvents. By XRD and SEM, the phase and morphologies were clearly detected. Meanwhile, this material can be used to decolorize MB dye solution without any kind of light source and this material was studied as catalyst for the degradation of $\mathrm{MB}$ on different temperatures, and finally found that temperature can influence the decoloring degree to a great extent.

\section{References}

1. Itoh H, Yoshida K, Masunaga S (2007) Quantitative identification of unknown exposure pathways of phthalates based on measuring their metabolites in human urine. Environ Sci Technol 41: 4542-4547.

2. Mahmoodi NM, Hayati B, Arami M, Firoozmehr Mazaheri (2010) Single and Binary System Dye removal from Colored Textile Wastewater by a Dendrimer as a Polymeric Nanoarchitecture: Equilibrium and Kinetics. J Chem Eng Data 55: $4660-4668$

3. Zushi Y, Ye F, Motegi M, Nojiri K, Hosono S, et al. (2011) Spatially detailed survey on pollution by multiple perfluorinated compounds in the Tokyo Bay basin of Japan. Environ Sci Technol 45: 2887-2893.

4. Zhuang X, Wan Y, Feng CM, Ying Shen, Dongyuan Zhao (2009) Highly efficient Adsorption of Bulky Dye Molecules in Wastewater on Ordered Mesoporous Carbons. Chem Mater 21: 706-716.

5. Tokumura M, Katoh T, Ohata H, Yoshinori Kawase (2009) Dynamic modeling and simulation of ozonation in a semibatch bubble column reactor: decolorization and mineralization of azo dye orange II by ozone. Ind Eng Chem Res 48: 7965-7975.

6. Raji JR, Palanivelu K (2011) Sunlight-induced photocatalytic degradation of organic pollutants by carbon-modified nanotitania with vegetable oil as precursor. Indus Eng Chem Res 50: 3130-3138.

7. Lim CL, Morad N, Teng TT, Ismail N (2009) Treatment of Terasil Red R dye wastewater using $\mathrm{H} 2 \mathrm{O} 2$ /pyridine/Cu(II) system. J Hazard Mater 168: 383-389.

8. Mccullagh C, Robertson PK (2006) Photosensitized Destruction of Chlorella vulgaris by Methylene Blue or Nuclear Fast Red Combined with Hydrogen Peroxide under Visible Light Irradiation. Environ Sci Technol 40: 2421-2425.

9. He YJ, Yu XY, Zhao XL (2007) Synthesis of hollow CuS nanostructured microspheres with novel surface morphologies. Materials Letters 61: 30143016.

10. Chen YC, Shi JB, Wu C, Chih Jung Chen, Ting Lin Ya, et al. (2008) Fabrication and optical properties of CuS nanowires by sulfuring method. Materials Letters 62: $1421-1423$

11. Kalyanikutty KP, Nikhila M, Maitra U, CNR Rao (2006) Hydrogel-assisted synthesis of nanotubes and nanorods of CdS, ZnS and CuS, showing some evidence for oriented attachment. Chemical Physics Letters 432: 190-194.

12. Li Z, Mi LW, Chen W, Hou H, Liu C, et al. (2012) Three-dimensional CuS hierarchical architectures as recyclable catalysts for dye decolorization. Cryst Eng Comm 14: 3965-3971. 